\title{
ASSESSMENT OF CAVITATING FLOW AGGRESSIVENESS ON A HYDROFOIL : EXPERIMENTAL AND NUMERICAL APPROACHES
}

\author{
Jean-Bastien Carrat* \\ Univ. Grenoble Alpes, \\ Grenoble INP† CNRS, LEGI \\ F-38000 Grenoble, France \\ Email: jean-bastien.carrat@legi.grenoble-inp.fr
}

\author{
Regiane Fortes-Patella \\ Univ. Grenoble Alpes, \\ Grenoble INP ${ }^{\dagger}$, CNRS, LEGI \\ F-38000 Grenoble, France
}

\author{
Jean-Pierre Franc \\ Univ. Grenoble Alpes, \\ Grenoble INP ${ }^{\dagger}$, CNRS, LEGI \\ F-38000 Grenoble, France
}

\begin{abstract}
The aggressiveness of a partial cavity on a hydrofoil in a cavitation tunnel is investigated from a joint numerical and experimental analysis. The numerical approach is based on a homogeneous equilibrium model and a barotropic law for the liquid/vapor mixture [1]2] for cold water. The unsteady behavior of the cavity appears in good agreement with experiments although the maximum cavity length is underestimated and the cloud shedding frequency overestimated. The flow aggressiveness is estimated by using the energy approach proposed by Fortes-Patella et al. [3] 4]. The technique predicts a maximum in flow aggressiveness located in the region where the cloud cavity is shed and increases as a power of the flow velocity between 2 and 3 .
\end{abstract}

\section{NOMENCLATURE}

$c$ reference length equal to the chord length, $c=100 \mathrm{~mm}[\mathrm{~mm}]$

$c_{\min }$ minimum speed of sound $[\mathrm{m} / \mathrm{s}]$

$E$ potential energy [J]

$f$ shedding frequency $[\mathrm{Hz}]$

$g$ pixel gray level at an instant $\mathrm{t}[-]$

$g_{\text {mean }}$ mean gray level over the span at an instant $\mathrm{t}[-]$

$h$ distance perpendicular to the wall [m]

$i$ incidence of the hydrofoil $\left[{ }^{\circ}\right]$

$l$ maximum cavity length [mm]

$p_{v} \quad$ vapor pressure $[\mathrm{Pa}]$

$p_{u p} \quad$ upstream pressure $[\mathrm{Pa}]$

\footnotetext{
*Address all correspondence to this author.

${ }^{\dagger}$ Institute of Engineering Univ. Grenoble Alpes
}

$p \quad$ pressure in a cell $[\mathrm{Pa}]$

$P$ potential power [W]

$P_{3 d}$ potential power density [W.m $\left.{ }^{-3}\right]$

$P_{2 d}$ areal potential power density [W. $\left.{ }^{-2}\right]$

$P_{\text {mean }}$ mean aggressiveness intensity $\left[\mathrm{W} \cdot \mathrm{m}^{-2}\right]$

St Strouhal number $S t=f c / V$ (based on the chord length) or $S t=f l / V$ (based on the cavity length) $[-]$

$T$ temperature $\left[{ }^{\circ} \mathrm{C}\right]$

$T_{\text {trans }}$ duration of the numerical transient [s]

$T_{a}$ analysis duration [s]

$V$ flow velocity in the test section $[\mathrm{m} / \mathrm{s}]$

$V_{\text {vap }}$ total vapor volume in the computational domain $\left[\mathrm{m}^{3}\right]$

$V_{\text {cell }} \quad$ volume of a cell $\left[\mathrm{m}^{3}\right]$

$\alpha$ void fraction, $\alpha=\left(\rho_{l}-\rho\right) /\left(\rho_{l}-\rho_{v}\right)[-]$

$\Delta S$ reference area $\left[\mathrm{m}^{2}\right]$

$\Delta t \quad$ numerical time step $\Delta t=0.2 * c / V$ [s]

$\Delta z \quad$ width of the central part studied experimentally [mm]

$\rho_{l}$ liquid density $\left[\mathrm{kg} \cdot \mathrm{m}^{-3}\right]$

$\rho_{v} \quad$ vapor density $\left[\mathrm{kg} \cdot \mathrm{m}^{-3}\right]$

$\rho$ mixture density $\left[\mathrm{kg} \cdot \mathrm{m}^{-3}\right]$

$\sigma$ upstream cavitation number in the test section [-]

\section{INTRODUCTION}

For partial cavitation, the cavitating flow aggressiveness is connected to the unsteadiness of the cavity. In particular, Reisman et al [5] pointed out that the cloud cavity shed by a cavity was responsible for cavitation erosion. 


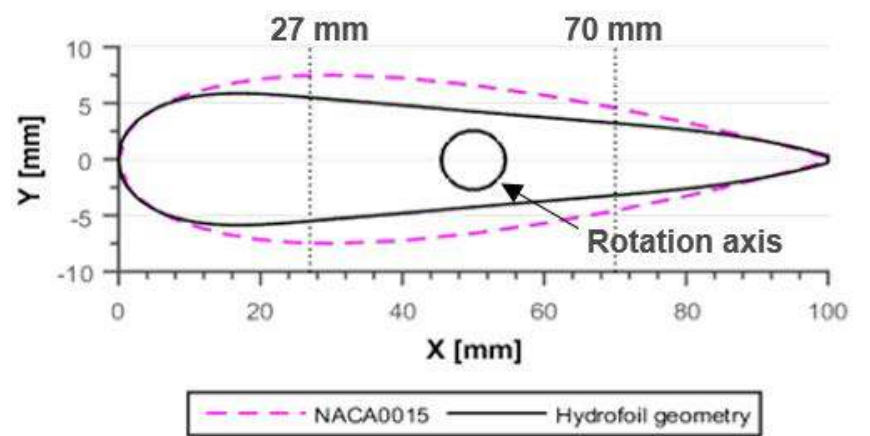

FIGURE 1. HYDROFOIL GEOMETRY

In order to simulate the behavior of partial cavitation, the in-house 2D cavitating unsteady code "IZ" is used in this paper. In parallel a series of experimental measurements has been performed in the hydrodynamic tunnel of the LEGI (Laboratory of Geophysical and Industrial Flows). The post-treatment applied on the experimental and numerical results will be explained. Then the global behavior observed experimentally and numerically will be compared. Finally the numerical approach for estimating cavitation aggressiveness, proposed by Fortes-Patella et al. [4] will be applied on this particular hydrofoil.

\section{HYDROFOIL GEOMETRY}

The choice of the hydrofoil shape has been based on experimental and numerical considerations.

In order to be able to test various types of sensors the hydrofoil has been designed with a large flat area. On the same time, the hydrofoil should allow us to have different cavitation patterns and levels of cavitation aggressiveness. Based on these considerations and after a pre-study done by using the 2D cavitating unsteady code "IZ" [1, 2, 4,6] the hydrofoil geometry shown in Fig. 11 has been selected.

The hydrofoil is symmetrical with the same leading edge radius as a NACA0015, i.e. $7 \%$ of the chord length. Its chord length is $c=100 \mathrm{~mm}$ and its maximum thickness is $12 \%$ of the chord length. The flat area is located between $27 \%$ and $70 \%$ of the chord length, which provides room for instrumentation. Its rotation axis is at mid chord. A smooth transition between the flat and curved part of the hydrofoil is ensured by continuity of the first and second derivative of the upper and lower hydrofoil surface.

\section{EXPERIMENTAL SET UP}

Experiments have been conducted in the water tunnel of the LEGI laboratory.

The length, width and height of the test section illustrated in

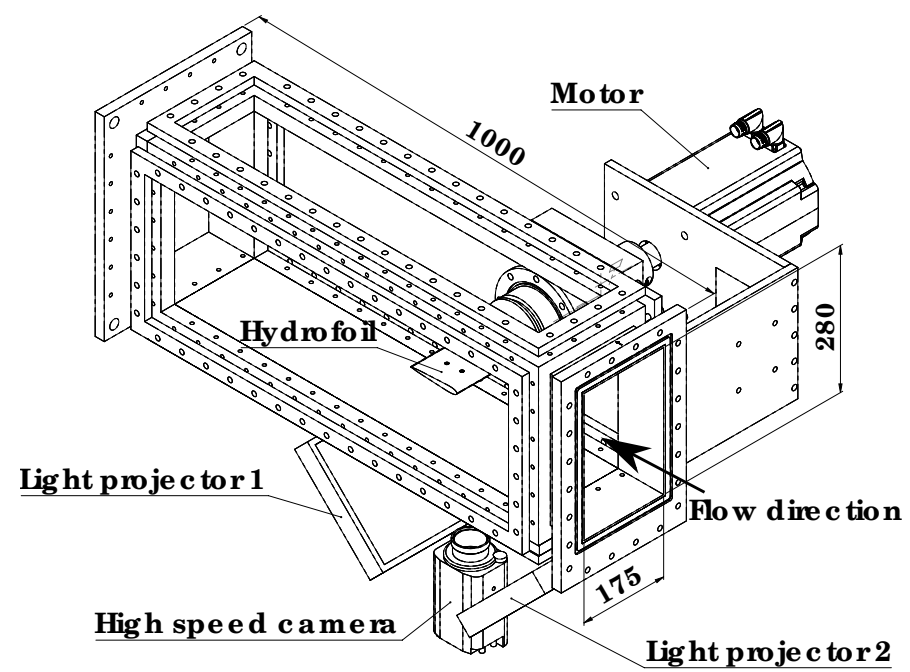

FIGURE 2. SCHEME OF THE EXPERIMENTAL SET UP

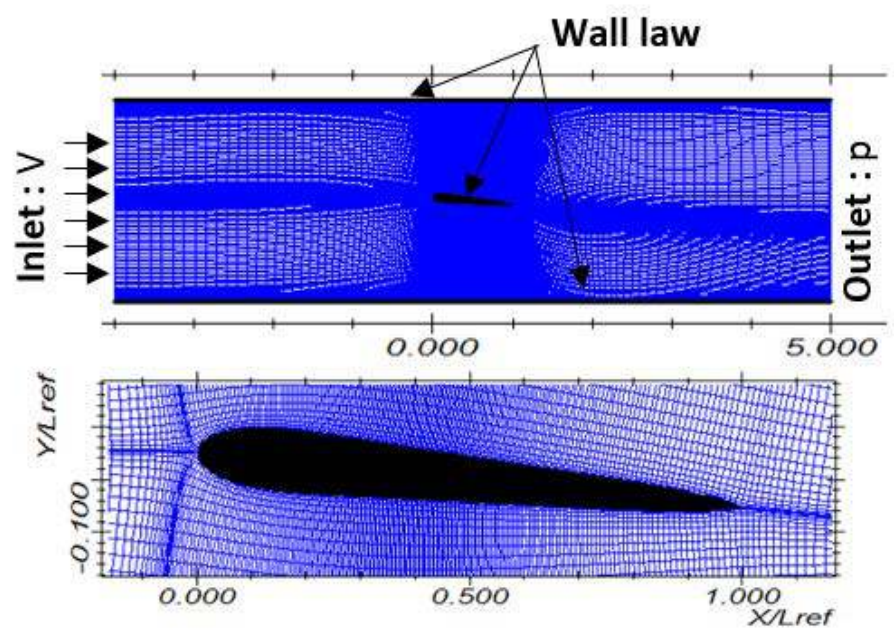

FIGURE 3. MESH IN THE TEST SECTION (TOP) AND AROUND THE FOIL (BOTTOM)

Fig. 2 are respectively $1000 \mathrm{~mm}, 175 \mathrm{~mm}$ and $280 \mathrm{~mm}$. The hydrofoil rotation axis is placed at one third of the length and half of the height of the test section. The incidence is fixed with a brushless motor controled by a variator. Every side of the test section is in plexiglass. High speed videos are taken from the bottom by using a high speed camera (MIRO C310), showed in Fig. 2, at a framerate of $3200 \mathrm{fps}$. Light is provided by 2 projectors inclined at $45^{\circ}$. The tunnel is equipped by 2 pressure sensors (one upstream and one downstream of the test section), a flowmeter and a temperature sensor. From these measurements, the upstream 
cavitation number $\sigma$ in the test section is evaluated by :

$$
\sigma=\frac{p_{u p}-p_{v}(T)}{\frac{1}{2} \rho(T) V^{2}}
$$

A series of experimental measurements have been made for upstream velocities of 6,8 and $10 \mathrm{~m} / \mathrm{s}$ and upstream cavitation numbers decreasing from 2.2 to 0.3 . Several angles of attack have been tested and the results for $4^{\circ}, 6^{\circ}$ and $8^{\circ}$ are presented in this paper. Each video corresponds to 8300 frames and $2.5 \mathrm{~s}$ duration.

The uncertainties on $\mathrm{V}$ and $\sigma$ are respectively of $0.01 \mathrm{~m} / \mathrm{s}$ and 0.02 .

\section{CFD CALCULATION}

The numerical study uses the in-house 2D code "IZ". The Unsteady Reynolds Averaged Navier-Stockes equations are solved with the assumption of a homogeneous fluid with variable density. The mixture density $\rho$ is defined as a function of the void fraction $\alpha$ :

$$
\rho=\alpha \rho_{v}+(1-\alpha) \rho_{l}
$$

A modified k- $\varepsilon$ RNG turbulence model (described in detail by Coutier-Delgosha et al [2]) with standard wall functions is employed. A barotropic equation of state, $\rho(p)$ is used for modelling cavitation and closing the equation system, defined in [1 6] by :

$$
\rho=\frac{\rho_{l}+\rho_{v}}{2}+\frac{\rho_{l}-\rho_{v}}{2}\left[1+\sin \left(\frac{2\left(p-p_{v}\right)}{c_{\min }^{2}\left(\rho_{l}-\rho_{v}\right)}\right)\right]
$$

This law ensures a smooth transition between liquid and vapour and is mainly controlled by its maximum slope related to the minimum speed of sound $c_{\min }$ in the mixture. In the present study, $c_{\min }$ is fixed at $1 \mathrm{~m} / \mathrm{s}$. Besides this CFD code has already been validated against numerous experiments and geometries such as Venturi, hydrofoil and hydrofoil cascade [2 4467 . 6 ].

The calculations are carried out using a structured mesh, a H-grid, composed of 290x119 cells refined around the hydrofoil on the upper and lower walls as shown in Fig. 3. At the wall, the dimensionless wall distance $y+$ lies between 20 and 50 and the standard law of the wall could be applied. A velocity and a pressure condition are imposed respectively at the inlet and outlet of the computational domain.

\section{POST-TREATMENT}

The next sections explain the methodology used for determining the cavity length $l$ and the shedding frequency $f$ numer-
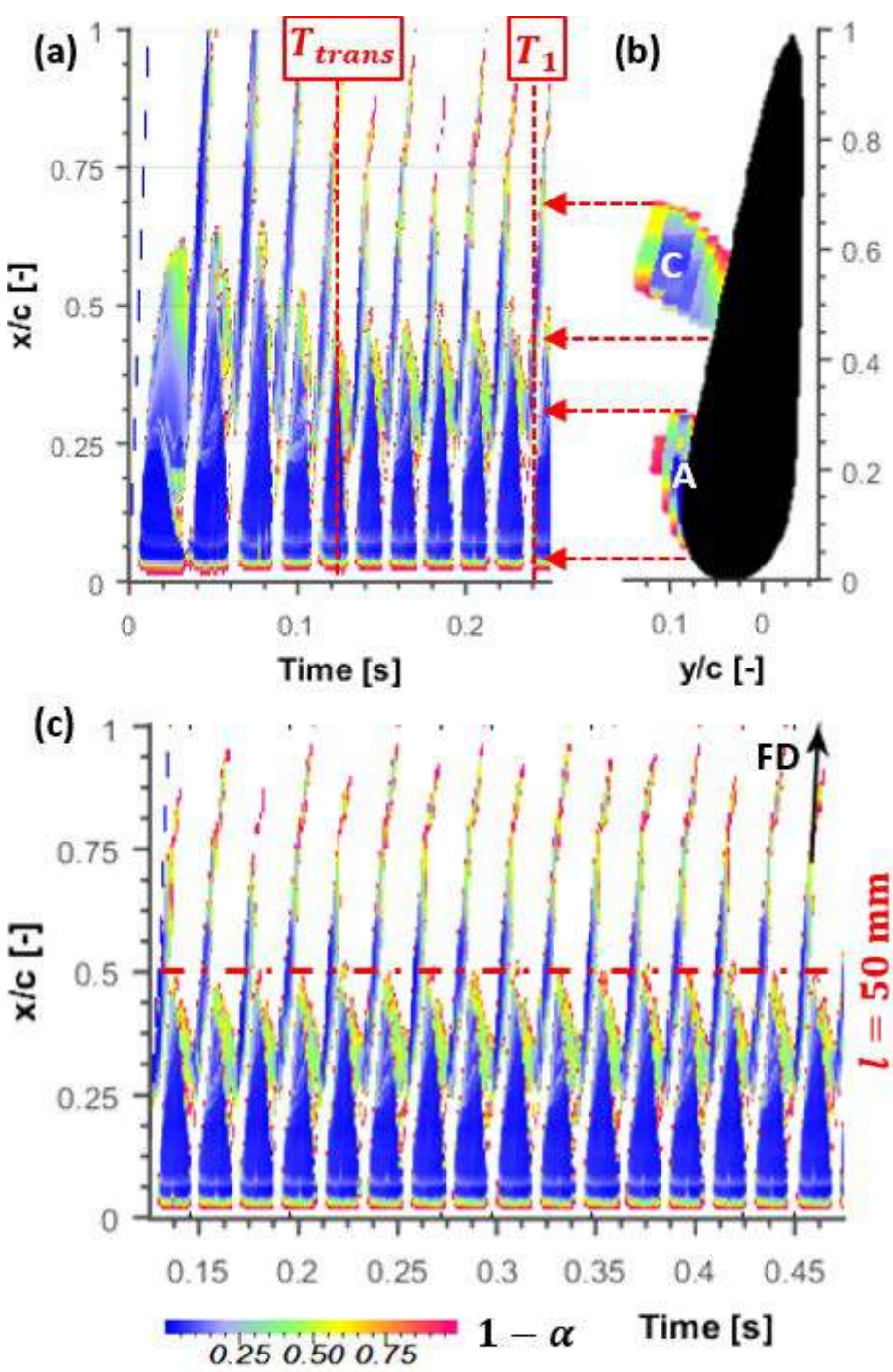

\section{A : Attached cavity / C : Cloud cavity / FD : flow direction}

FIGURE 4. (a) SPACE-TIME DIAGRAM OF VOID FRACTION BETWEEN 0 AND $0.25 \mathrm{~S}$. (b) VOID FRACTION DISTRIBUTION AT $t=t_{1}$. (c) SPACE-TIME DIAGRAM OF VOID FRACTION BETWEEN 0.125 AND $0.475 \mathrm{~S}$. THE VOID FRACTION SHOWN AT EACH POINT (X, T) IS THE MINIMUM VALUE OF VOID FRACTION ALONG THE LINE $X=$ CONSTANT PERPENDICULAR TO THE FOIL IN THE $(x, y)$ DOMAIN. BLUE AND WHITE ARE RESPECTIVELY FOR PURE VAPOR AND LIQUID. (NUMERICAL POINT : $i=4^{\circ}, V=8 \mathrm{~m} / \mathrm{s}$ AND $\sigma=1.04$ )

ically and experimentally. The methodology is explained in the case of an incidence $i=4^{\circ}$, a velocity $V=8 \mathrm{~m} / \mathrm{s}$, and a cavitation number $\sigma=1.04$ for the simulation and 1.09 for the experiment. 

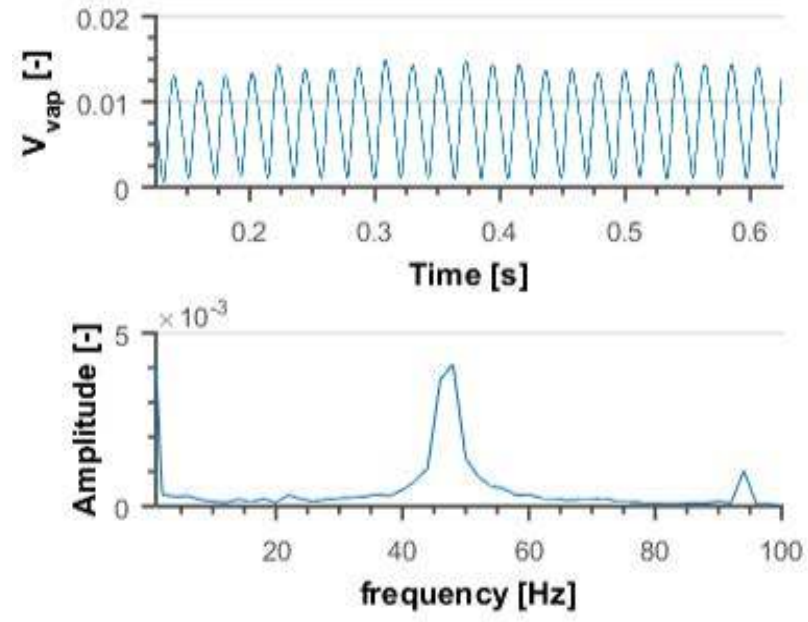

FIGURE 5. (a) TIME EVOLUTION OF THE TOTAL VAPOR VOLUME BETWEEN 0.125 AND 0.63 S. (b) FFT OF THE TIME EVOLUTION OF THE TOTAL VAPOR VOLUME BETWEEN 0.125 AND 0.63. (NUMERICAL POINT : $i=4^{\circ}, V=8 \mathrm{~m} / \mathrm{s}$ AND $\sigma=1.04$ )

\section{Numerical methodology}

Numerical calculations start from stationnary non cavitating conditons. The outlet pressure is slowly decreased in order to get the desired $\sigma$.

Because the transient period does not represent the desired operating point, all analyses have been made after this settle time. The duration of the transient time is defined as the limit between a non periodic and a periodic oscillation of the cavity. From Fig. 4.(a), the duration of the initial transient flow is determined as about $T_{\text {trans }}=0.125 \mathrm{~s}$.

The total volume of vapour in the computational domain is a good way to estimate the shedding frequency, because it takes into account the growth and collapse of the cavitation structures in the computational domain.

The time evolution of the total vapour volume between 0.125 and $0.63 \mathrm{~s}$ is periodic as shown in Fig. 5(a). By applying a Fast Fourier Transformation to the total vapour volume, the frequency spectrum can be determined (see Fig. 5. (b)), with a peak centered around the shedding frequency, equal to $f=48.0 \mathrm{~Hz}$ in this particular case.

From Fig. 4.(c), the cavity length can be evaluated at any time. The cavity length $l$, considered later, is defined as the maximum length of the cavity before detachment by the re-entrant jet. For the case in Fig. 4 the maximum cavity length is equal to $l / c=0.50$.

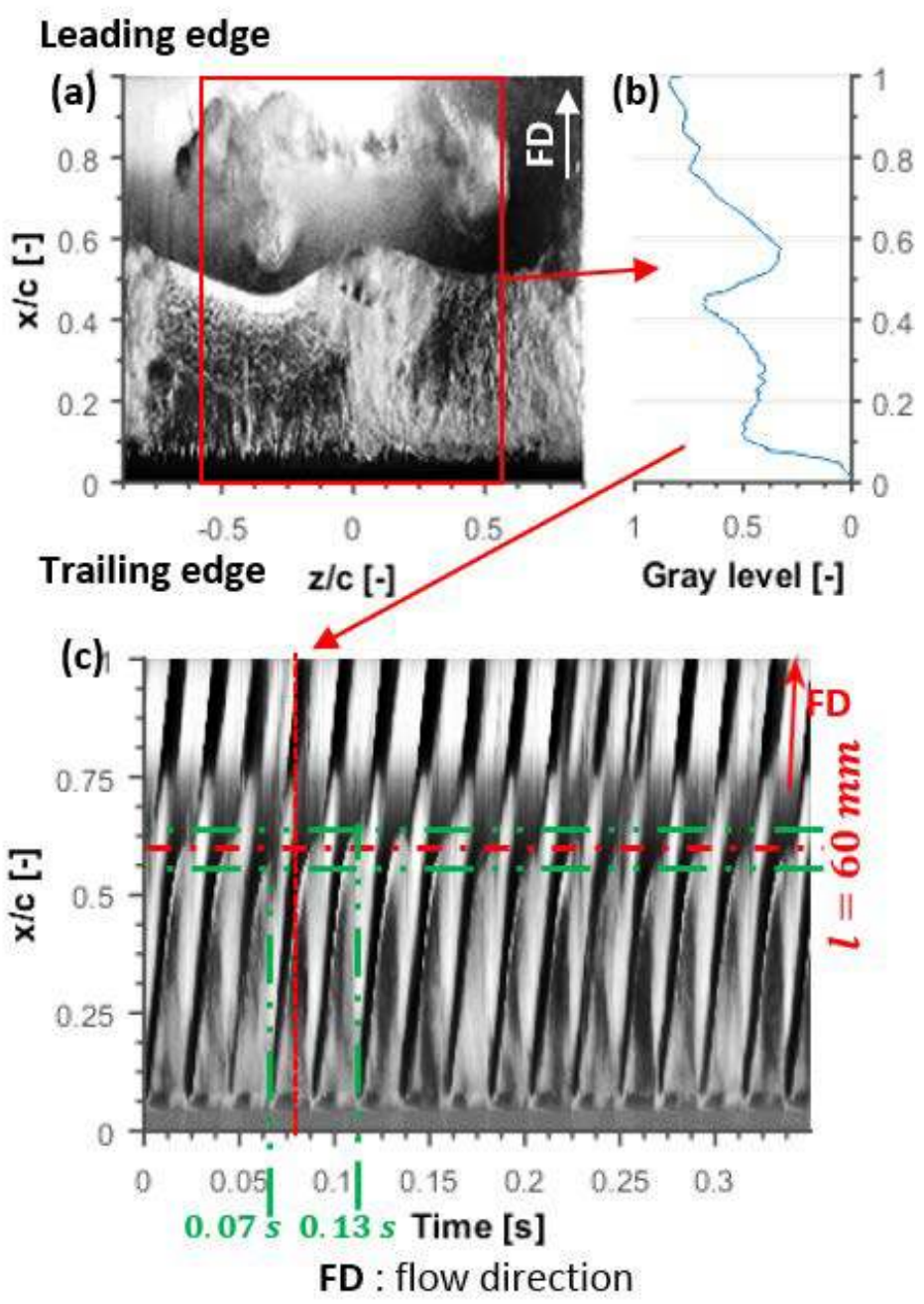

FIGURE 6. (a) SNAPSHOT AT $t=0.08 \mathrm{~s}$. (b) MEAN GRAY PROFILE IN THE REDUCED SNAPSHOT AT $\mathrm{t}=0.08 \mathrm{~S}$. (c) SPACE-TIME DIAGRAM OF GRAY LEVEL BETWEEN 0 AND $0.35 \mathrm{~S}$. BLACK AND WHITE ARE RESPECTIVELY A GRAY LEVEL OF 0 AND 1. $\left(i=4^{\circ}, V=8 \mathrm{~m} / \mathrm{s}\right.$ AND $\left.\sigma=1.09\right)$

\section{Experimental methodology}

Figure 6 illustrates the experimental post-treatment based on high speed video for a given operating point defined by $V=8 \mathrm{~m} / \mathrm{s}, \sigma=1.09$ and $i=4^{\circ}$. The same kind of image processing as Prothin et al. [9] is used.

The analysis is limited to a central part $\Delta z=60 \mathrm{~mm}$ wide, represented by the red rectangle in Fig. 6.(a) in order to get rid of side effects along the tunnel wall. Therefore the mean gray profile $g_{\text {mean }}$ along the chord at $t=0.08 \mathrm{~s}$, shown in Fig. 6.(b), is estimated by the spatial averaging of the gray profile $g$ over the 
(a)

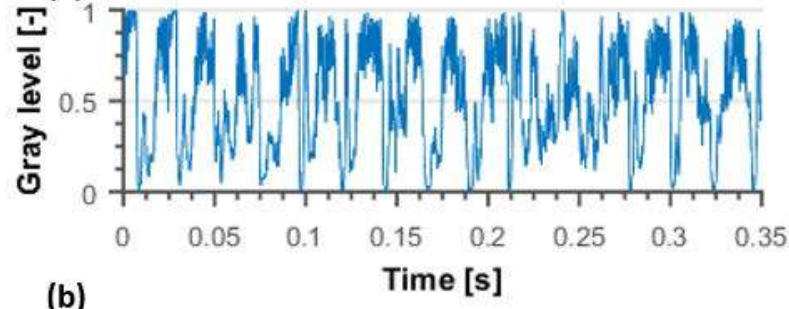

(b)

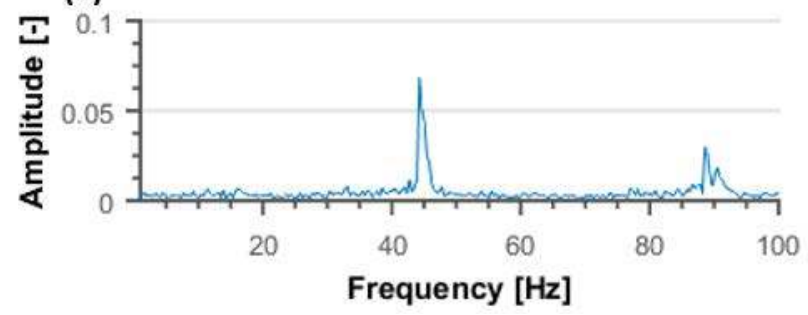

FIGURE 7. (a) EXAMPLE OF THE TIME EVOLUTION OF THE MEAN GRAY AT $25 \%$ OF THE CHORD LENGTH BETWEEN 0 AND $0.35 \mathrm{~s}$. (b) FFT OF THE SPACE-TIME DIAGRAM OF THE MEAN GRAY LEVEL ACROSS TIME ON THE $2.5 \mathrm{~s}$ RECORDING. (EXPERIMENTAL POINT $: i=4^{\circ}, V=8 \mathrm{~m} / \mathrm{s}$ AND $\sigma=1.09$ )

span in the reduced snapshot :

$$
g_{\text {mean }}(x, t)=\frac{1}{\Delta z} \int_{-\Delta z / 2}^{+\Delta z / 2} g(x, z, t) \cdot d z
$$

The operation is repeated for every frame and provides the spacetime diagram of the mean gray level shown in Fig. 6(c).

The mean gray profile oscillation at $25 \%$ (see Fig. [7(a)) of the chord length is due to the periodic behavior of the partial cavity. For every point along the chord the mean gray evolution is almost the same as the one shown in Fig. (7) The FFT of the space-time diagram (in Fig. 6(c)) across time gives the spectral distribution in Fig. 7 with a major peak centered around the shedding frequency $f=44.3 \mathrm{~Hz}$.

The peak for the numerical FFT in Fig. 5] is wider than the experimental one because the sample duration for the FFT calculation is smaller for the numerical analysis.

In the time evolution of the mean gray level in Fig. 6(b) the maximum cavity length as defined in the previous section is not exactly the same for every shedding. As an example, the maximum measured cavity length is $l / c=0.57$ at $\mathrm{t}=0.07 \mathrm{~s}$, whereas it is $l / c=0.64$ at $\mathrm{t}=0.13 \mathrm{~s}$. As a consequence, the cavity length is estimated from the average between the two former values with an uncertainty of $\pm 5 \%$ of the chord, which gives $l / c=0.60 \pm 0.05$. (a)

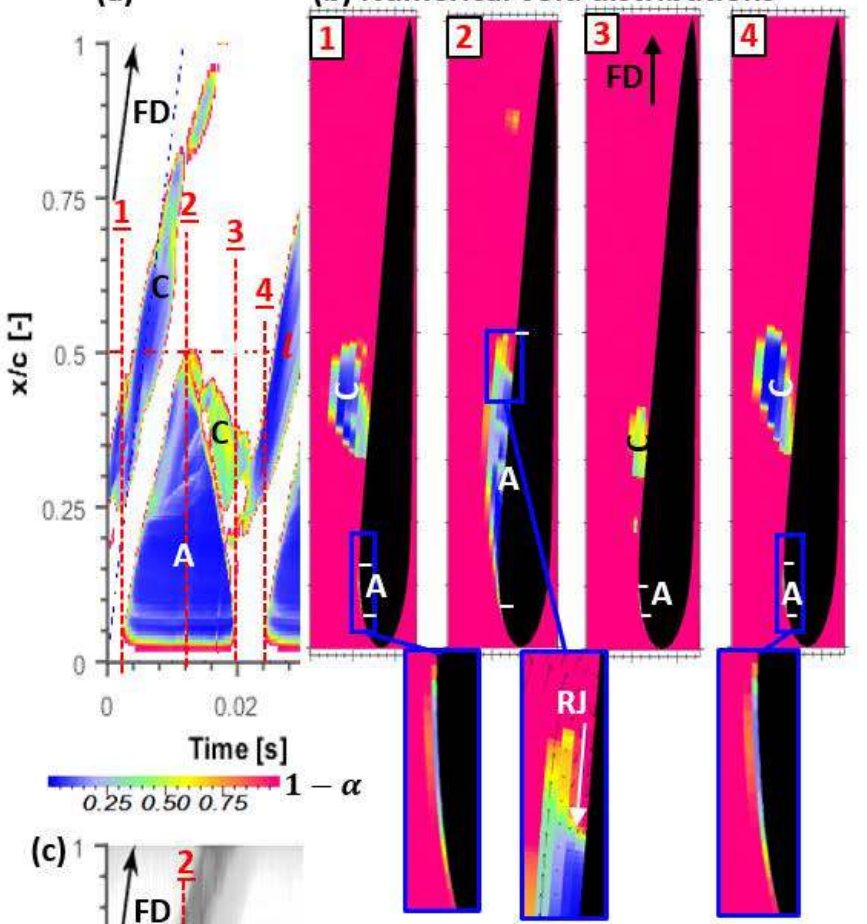

(d) Experimental snapshots

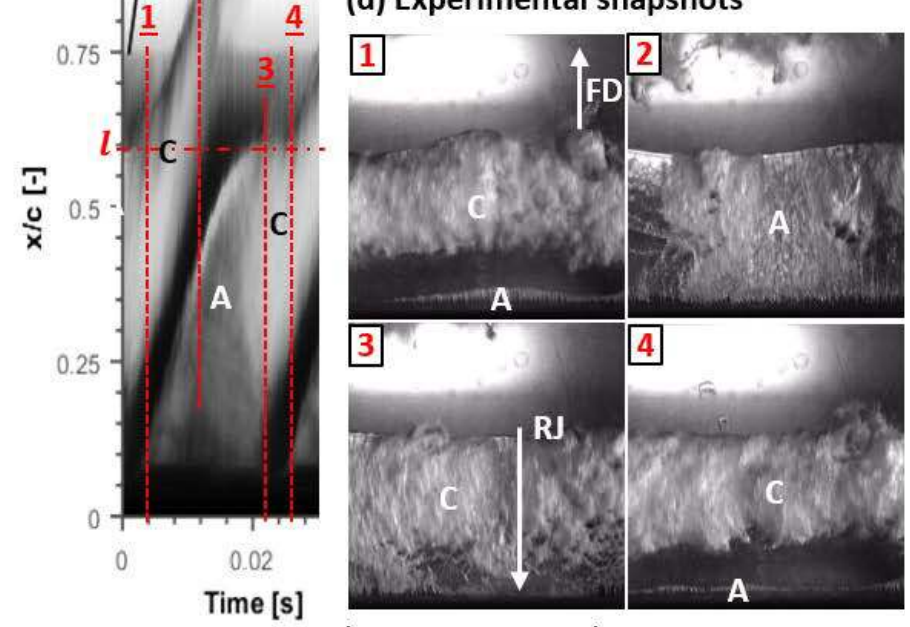

A : Attached cavity / C : Cloud cavity / RJ : Re-entrant jet

/ FD : flow direction

FIGURE 8. COMPARISON BETWEEN NUMERICAL ( (a) AND (b) ) AND EXPERIMENTAL RESULTS ( (c) AND (d) ) ON CAVITY DYNAMICS FOR $i=4^{\circ}, V=8 \mathrm{~m} / \mathrm{s}$ AND A NUMERICAL AND EXPERIMENTAL CAVITATION NUMBER OF $\sigma=1.04$ AND 1.09. 1. INCEPTION OF THE LEADING EDGE CAVITY; 2. MAXIMUM CAVITY LENGTH; 3. CAVITY BREAK-OFF BY THE REENTRANT JET; 4. INCEPTION OF A NEW LEADING EDGE CAVITY. 


\section{GLOBAL ANALYSIS}

\section{Cavity dynamics}

The various stages of the shedding mechanism connected to the development of a re-entrant jet, as described by Le et al. [10], are observed experimentally and numerically in Fig. 8

At instant 1, an incipient cavity and a cloud cavity shed during the previous oscillation are visible. Between instants 1 and 2 , the attached cavity is growing. At instant 2 , the attached cavity reaches its maximum length and the re-entrant jet starts developing at the end of the cavity. The re-entrant jet is visible numerically in Fig. 8(b) in the zoom at the end of the cavity. Between 2 and 3, the re-entrant jet is moving backward to the foil leading edge. At instant 3 , it reaches the front of the cavity and cuts it, creating the cloud cavity, which is potentially erosive as discussed later. Between instants 3 and 4, there is almost no attached cavity and the cloud cavity is convected by the flow. Instant 4, is almost identical to instant 1 with the start of a new shedding.

Numerical and experimental results are very similar. On the whole, the behavior of the partial cavity is globally well predicted by the simulations. Even if the oscillation period is the same and equal to $22 \mathrm{~ms}$, the duration of each stage is not the same experimentally and numerically. The growth of the attached cavity between instants 1 and 2 (see Fig. 8 (a) and (c)) represents 76 $\%$ of the shedding duration for the experiment while it is only 42 $\%$ for the simulation. Le et al. [10] observed on a plano-convex foil a growth during $2 / 3$ of the shedding duration, which confirms our measurement. On the other hand the duration of the cavity break-off by the re-entrant jet is 5 time longer numerically than experimentally.

\section{Numerical and experimental comparisons}

Experimental and numerical analyses have been done for different cavitating conditions. The upstream velocity is fixed at 6,8 and $10 \mathrm{~m} / \mathrm{s}$. The numerical and experimental upstream cavitation number varies respectively from 0.70 to 1.34 and 0.70 to 1.94. Several angles of attack are tested : $4^{\circ}, 6^{\circ}$ and $8^{\circ}$. For the moment only $4^{\circ}$ and $6^{\circ}$ are simulated. For each operating point, the cavity length and shedding frequency are determined from both experiments and simulations by using the previous methodology.

The results for the cavity length are plotted in Fig. 9 Previous measurements from Kawanami et al. [11] for a NACA0015 hydrofoil with a chord length of $80 \mathrm{~mm}$ are added to this graph.

Kawanami et al. [11] observed an independence of the maximum cavity length with the upstream velocity for a fixed angle in the range from 6 to $10 \mathrm{~m} / \mathrm{s}$. Our numerical and experimental results confirm this observation.

At the same angle of attack and cavitation number, the cavity length is always smaller numerically than experimentally. This difference could be partly explained by $3 \mathrm{D}$ effects not taken into

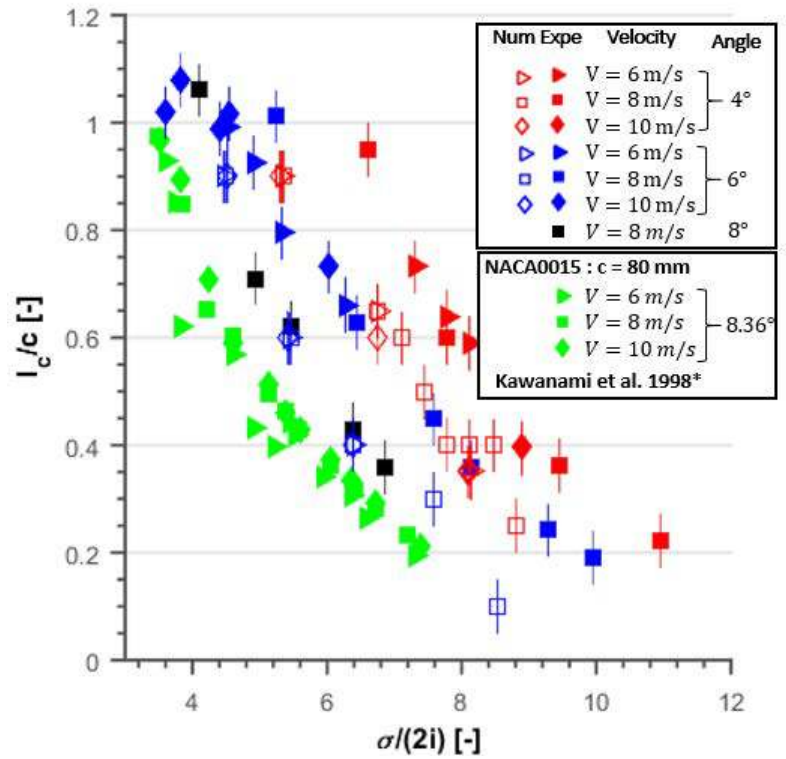

FIGURE 9. CAVITY LENGTH AS A FUNCTION OF $\sigma /(2 i)$. RED, BLUE, BLACK AND GREEN DOTS ARE FOR INCIDENCES OF $4^{\circ}$, $6^{\circ}, 8^{\circ}$ AND $8.36^{\circ}$. FILLED DOTS CORRESPOND TO EXPERIMENTAL RESULTS WHILE UNFILLED DOTS CORRESPOND TO NUMERICAL RESULTS.

account in the numerical simulation.

According to Arndt et al. [12] and Fujii. et al [13], two types of partial cavitation may occur for different hydrofoil shapes. The difference comes from the mechanism responsible for the cloud shedding. Type I oscillations for low values of $\sigma /(2 i)$ correspond to a bubbly shock wave. Type II oscillations for high values of $\sigma /(2 i)$ correspond to a re-entrant jet.

According to Arndt et al. [12, 14] the transition can be seen on the evolution of the Strouhal number based on the chord length $S t=f c / V$ as a function of $\sigma /(2 i)$, shown in Fig. 10 It is the point where the Strouhal number based on the chord length is increasing drastically from an almost constant value at 0.25 characterizing type I oscillation.

The points in green in Fig. 10 have been measured by Kawanami et al. [11] for a flow velocity of $\mathrm{V}=8 \mathrm{~m} / \mathrm{s}$ and an incidence of $8.36^{\circ}$. Our experimental results for $8^{\circ}$ are in pretty good agreement with these results, although the hydrofoil is different. For $\sigma /(2 i)<4$, the Strouhal number based on the chord length is almost constant at 0.25 and then increases with $\sigma /(2 i)$.

The same behavior is seen for $4^{c}$ irc and $6^{\circ}$ in Fig. 10 except that the transition limit is higher, respectively $\sigma /(2 i)=5$ and 5.5 both numerically and experimentally.

At a fixed incidence and cavitation number, the Strouhal number based on the chord length is almost independent of the flow velocity. So the shedding frequency is directly proportional 


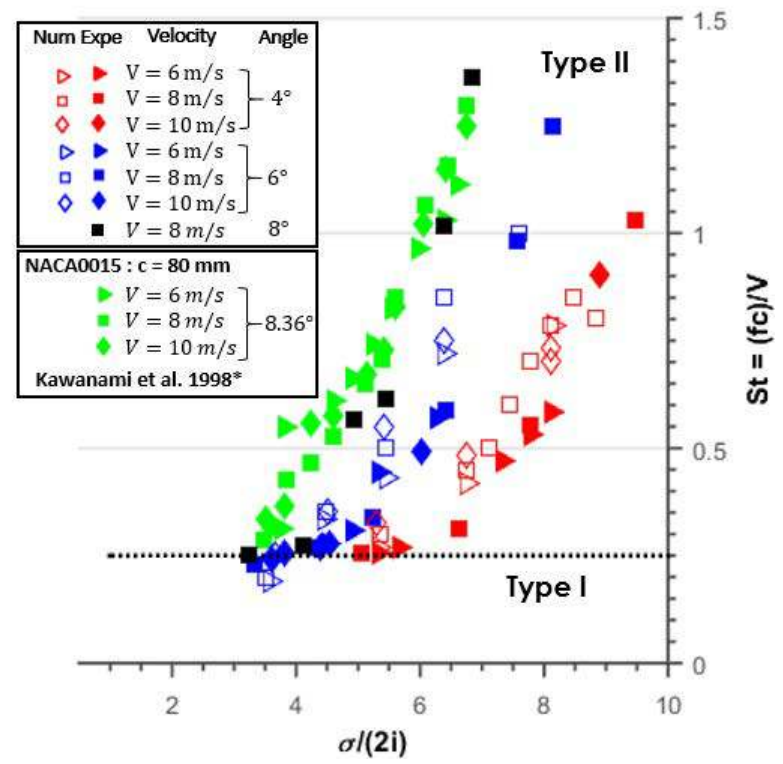

FIGURE 10. STROUHAL NUMBER BASED ON THE CHORD LENGTH $S t=f c / V$ AS A FUNCTION OF $\sigma /(2 i)$. RED, BLUE, BLACK AND GREEN DOTS ARE FOR INCIDENCES OF $4^{\circ}, 6^{\circ}, 8^{\circ}$ AND $8.36^{\circ}$. FILLED DOTS CORRESPOND TO EXPERIMENTAL RESULTS WHILE UNFILLED DOTS CORRESPOND TO NUMERICAL RESULTS.

to the flow velocity. For the same incidence, flow velocity and cavitation number, numerical calculations sligthly overestimate the shedding frequency compared to the experimental measurements.

The Strouhal number based on the cavity length, $S t=f l / V$, is presented in Fig. 11 as a function of $\sigma$. As a comparison, results from Kawanami et al. [11] are also plotted.

As expected, the Strouhal number is not much affected by the flow conditions such as incidence and upstream velocity. Our experimental points for $4^{\circ}, 6^{\circ}$ and $8^{\circ}$ and the same cavitation number are collapsing on the same curve regardless of the velocity. In addition, the Strouhal number based on the cavity length varies between 0.25 and 0.5 both numerically and experimentally, which is a typical range for the cloud cavitation instability [10, 15].

The former comparisons show that the numerical code is able to simulate correctly the global cavity dynamic with respect to the experimental observations. Nevertheless in the same hydrodynamic conditions (incidence, velocity and cavitation number) the cavity length is underestimated numerically. The shedding frequency is overestimated compared to the experimental measurements. Indeed for a type II oscillation, a longer cavity length means more time for the cavity break-off by the re-entrant and a lower shedding frequency. These differences were also ob-

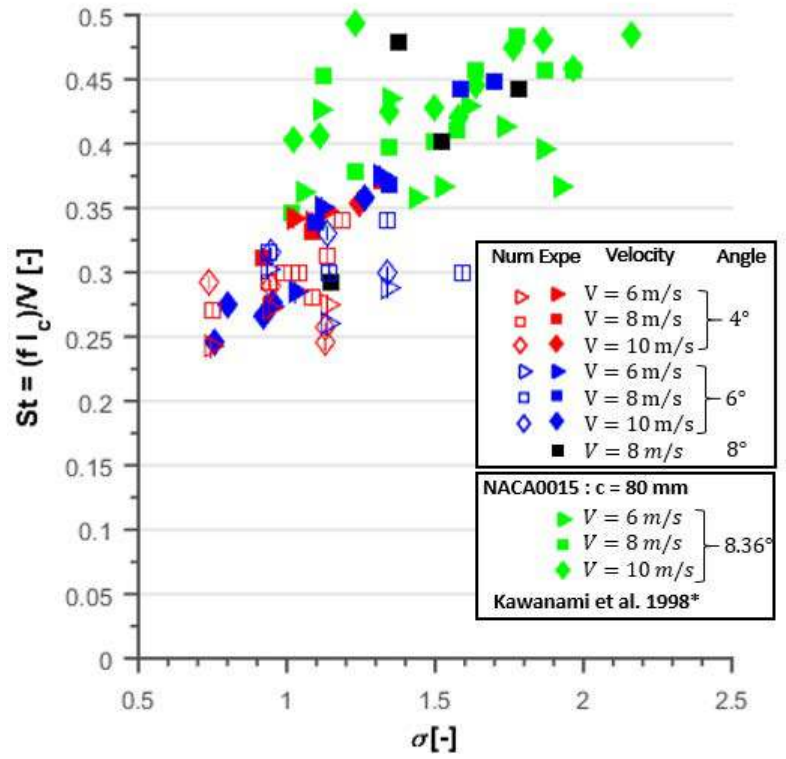

FIGURE 11. STROUHAL NUMBER BASED ON THE CAVITY LENGTH $S t=f l / V$ AS A FUNCTION OF $\sigma$. RED, BLUE, BLACK AND GREEN DOTS ARE FOR INCIDENCES OF $4^{\circ}, 6^{\circ}, 8^{\circ}$ AND 8.36 ${ }^{\circ}$. FILLED DOTS CORRESPOND TO EXPERIMENTAL RESULTS WHILE UNFILLED DOTS CORRESPOND TO NUMERICAL RESULTS.

served by Coutier-Delgosha et al. [6] with the same code in the case of a Venturi

\section{NUMERICAL AGGRESSIVENESS Modelling}

The erosion model developed by Fortes-Patella et al. [3 4] is used in this paper. A physical scenario describes the mechanism of cavitation erosion based on an energy approach.

Each vapor structure in a flow is characterised by its potential energy :

$$
E=\Delta p V_{\text {vap }}=\left(p-p_{v}\right) V_{\text {vap }}
$$

where $p$ is the surrounding pressure of the fluid.

Thus an instantaneous potential power is derived by a lagrangian derivative :

$$
P=\frac{d E}{d t}=V_{v a p} \frac{d \Delta p}{d t}+\Delta p \frac{d V_{v a p}}{d t}
$$

Leclerc et al. [16] showed that the $\Delta P$ variation is negligible compared to the variation of $V_{\text {vap }}$. Furthermore only the collapsing vapour structures (ie $d V_{v a p} / d t<0$ ) are considered. These 
assumptions lead to :

$$
P=-\Delta p \frac{d V_{v a p}}{d t}
$$

The minus sign is introduced in order to have a positive value.

The CFD unsteady calculation gives us the pressure $p$, velocity $V$, void fraction $\alpha$ and vapour volume $V_{\text {vap }}$ at every time step in a cell. In particular the vapour volume is related to the void fraction by $\alpha=V_{\text {vap }} / V_{\text {cell }}$.

So the potential power density in a cell can be written as:

$$
P_{3 d}=\frac{P}{V_{c e l l}}=-\Delta p \frac{d \alpha}{d t}
$$

Our goal is to estimate the aggressiveness at every point at the surface of the hydrofoil. The aggressiveness intensity at one point of the foil is the areal potential power density defined by integrating equation 8 :

$$
P_{2 d}=\int_{0}^{h} P_{3 d} \cdot d y
$$

where $h$ is a distance perpendicular to the wall. Physically, the aggresiveness intensity at one point of the surface includes the contribution of all the vapor structures within a distance $h$ to the wall. In our case, $h$ is big enough in order to take into acount all vapor structures.

$d \alpha / d t$ is calculated at every time step from the local mass conservation equation in a cell which gives :

$$
\frac{\partial \rho}{\partial t}+\operatorname{div}(\rho \vec{U})=0
$$

By using equations 2 and 10 it can be demonstrated that :

$$
\frac{d \alpha}{d t}=\frac{\rho}{\rho_{l}-\rho_{v}} \operatorname{div}(\vec{U})
$$

\section{Results}

In order to estimate the aggressiveness of the flow along the chord, the hydrofoil is divided in 50 numerical sensors $2 \mathrm{~mm}$ wide. On every sensor a temporal mean value of the aggressiveness intensity is evaluated as follows :

$$
P_{\text {mean }}=\frac{1}{T_{a}} \int_{0}^{T_{a}} P_{2 d} . d t
$$

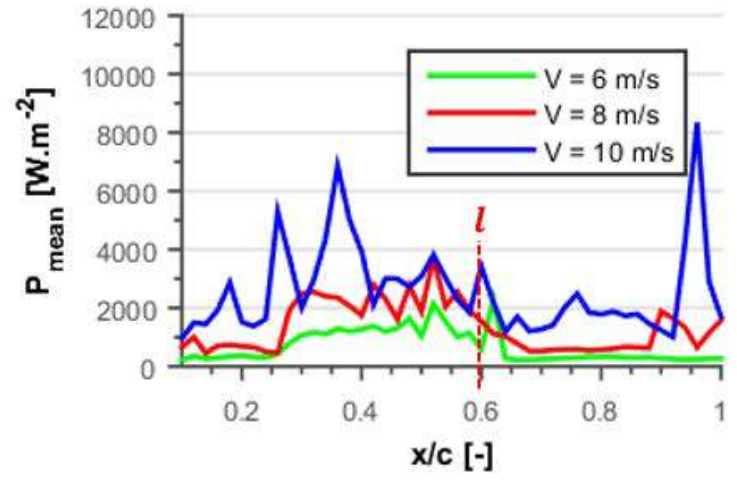

FIGURE 12. MEAN AGGRESSIVENESS INTENSITY PLOTTED AS A FUNCTION OF THE RELATIVE CHORD LENGTH FOR DIFFERENT FLOW VELOCITIES FOR AN INCIDENCE $i=4^{\circ}$ AND A CAVITATION NUMBER $\sigma=0.94$. THE CAVITY LENGTH IS EVALUATED EQUAL TO $60 \mathrm{~mm}$ FOR ALL CASES. THE SHEDDING FREQUENCIES FOR 6, 8 AND 10 m/s ARE RESPECTIVELY 25.1, 35.4 AND $43.3 \mathrm{~Hz}$. THE ANALYSIS PERIOD FOR EACH CASE IS $T_{a}=3 / f$. FURTHER NUMERICAL CALCULATIONS ARE IN PROGRESS IN ORDER TO MAKE CONCLUSION ON A LONGEST SAMPLE.

where $T_{a}$ is the analysis duration.

Figures 12 and 13 show the evolution of the mean aggressiveness intensity $P_{\text {mean }}$ along the chord for several velocities, incidences and cavitation numbers.

In particular for an incidence $i=4^{\circ}$ and a cavitation number $\sigma=0.94$ (Fig. 12), the most aggressive area tends to be the same for every velocity and is located between $15 \%$ and $65 \%$ of the chord length, whereas the cavity length is $l / c=60 \%$

Figure 13 shows the evolution of the mean aggressiveness along the chord for a case defined by an incidence $i=6^{\circ}$ and a cavitation number $\sigma=1.34$. The most aggressive area is located between $15 \%$ and $43 \%$ of the chord length, whereas the cavity length is $l / c=35 \%$

For both cases the most aggressive area is located around the cavity closure. These observations agree with the pressure measurements along the chord length made by Le et al. [17].

From Fig. 14 for a cavitation number $\sigma=0.94$ and an incidence $i=4^{\circ}$ the cloud cavity is located between $15 \%$ and $100 \%$ of the chord length regardless of the flow velocity. Between 1 and 2 in Fig. 14, the void fraction distribution along the chord varies strongly between two consecutive time steps. A lot of structures are collapsing during this period between $15 \%$ and $65 \%$ of the chord length, which results in the most aggressive area visible in Figs. 12 and 13. So the aggressiveness of the cavitating flow is mainly due to the shedded cloud as observed previously and pointed out numerically and experimentally by $\mathrm{Li}$ et al. [18] and Gavaises et al [19]. 


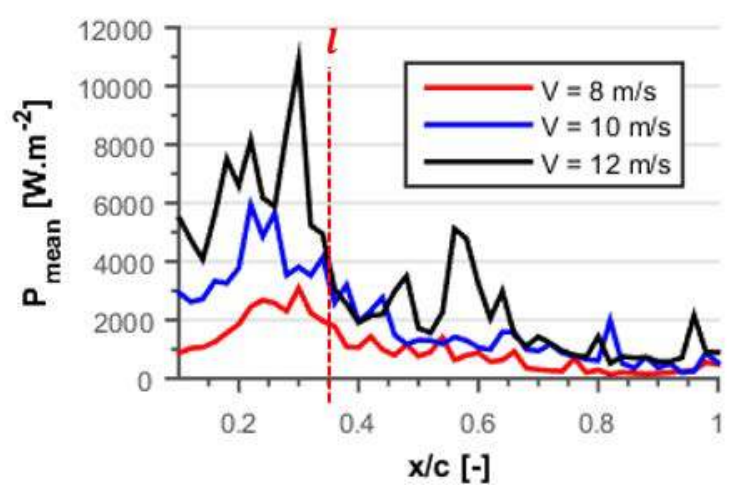

FIGURE 13. MEAN AGGRESSIVENESS INTENSITY PLOTTED AS A FUNCTION OF THE RELATIVE CHORD LENGTH FOR DIFFERENT FLOW VELOCITIES FOR AN INCIDENCE $i=6^{\circ}$ AND A CAVITATION NUMBER $\sigma=1.34$. THE CAVITY LENGTH IS EVALUATED EQUAL TO $35 \mathrm{~mm}$. THE SHEDDING FREQUENCY FOR 8, 10 AND $12 \mathrm{~m} / \mathrm{s}$ ARE RESPECTIVELY 68.0, 75.0 AND $97.0 \mathrm{~Hz}$. THE ANALYSIS PERIOD FOR EACH CASE IS $T_{a}=6 / f$. FURTHER NUMERICAL CALCULATIONS ARE IN PROGRESS IN ORDER TO MAKE CONCLUSION ON A LONGEST SAMPLE.

For every flow velocity and incidence, the maximum aggressiveness was determined and plotted as a function of the flow velocity in Fig. 15 .

Figure 15 shows that flow aggressiveness varies with a power of the flow velocity of the order of 2.2 for an incidence $i=4^{\circ}$ and a cavitation number of $\sigma=0.94$ and 3.2 for an incidence $i=6^{\circ}$ and a cavitation number of $\sigma=1.34$. A similar trend was observed by Leclercq et al. [16] on a different hydrofoil (NACA 65012) by using the same cavitation aggressiveness model and another numerical code.

\section{CONCLUSION}

Experimental and numerical investigations were performed for different cavitating conditions on a hydrofoil.

The shedding process was correctly predicted even though the shedding frequency was rather overestimated and the cavity length sligthly underestimated. The comparison of the characteristics of partial cavitation (cavity length, shedding frequency, Strouhal number) showed a pretty good agreement between experiments and simulations.

The flow aggressiveness was modelled based on the energetical approach of Fortes-Patella et al. [4]. The most aggressive areas were localized for two different cavitating conditions. Both are located in the region where the cloud cavity is shed by the hydrofoil, which confirms the erosive potential of cloud cavitation. In addition the velocity had a huge influence on the mean aggressiveness of the flow which increases as the power of the flow velocity, between 2 and 3 .

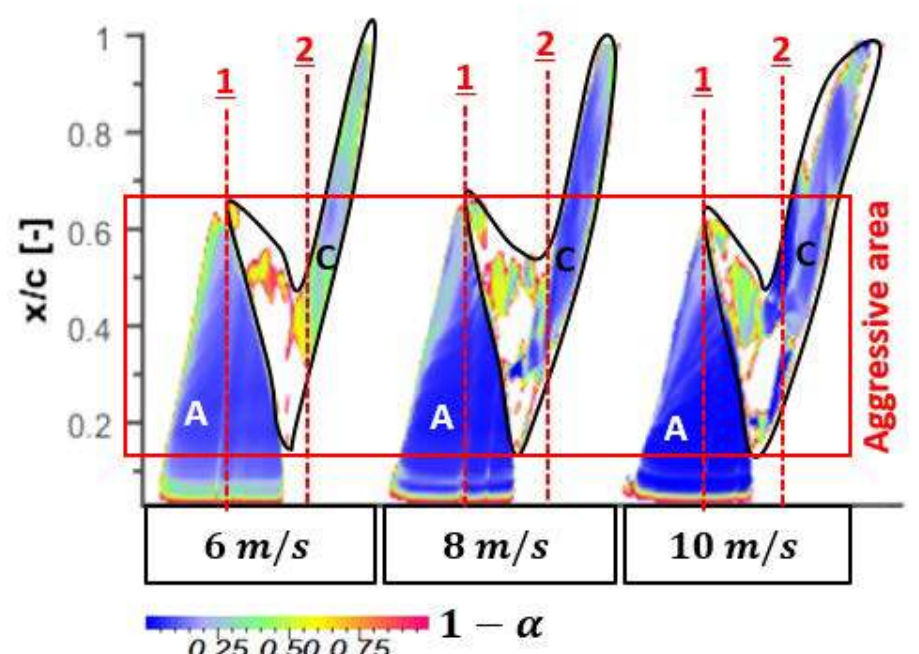

\section{A : Attached cavity / C : Cloud cavity}

FIGURE 14. SPACE-TIME DIAGRAMM OF THE VOID FRACTION FOR SEVERAL FLOW VELOCITIES $V=6,8,10 \mathrm{~m} / \mathrm{s} .\left(i=4^{\circ}\right.$ AND $\sigma=0.94$ )

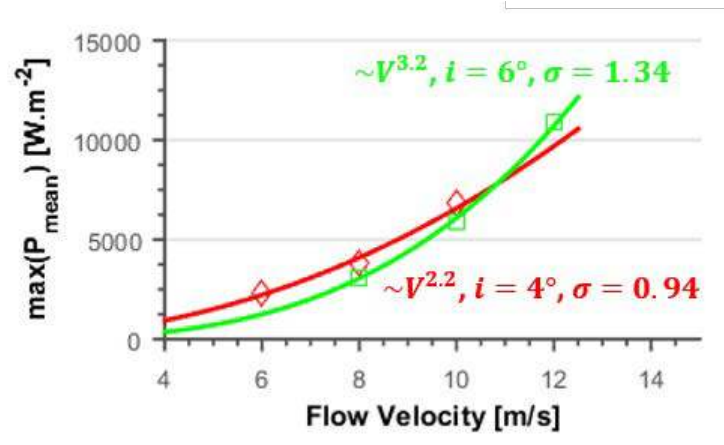

FIGURE 15. MAXIMUM VALUE OF THE MEAN AGGRESSIVENESS IN THE MOST AGGRESSIVE AREA PLOTTED AS A FUNCTION OF THE UPSTREAM VELOCITY.

In further work, a hydrofoil instrumented with pressure sensors fabricated from PVDF (PolyVinyliDene Fluoride) film will be used in the hydrodynamic tunnel of the LEGI. The pressure peaks due to the collapse of cavitation structures will be measured and compared to the numerical flow aggressiveness.

\section{AKNOWLEDGEMENTS}

The authors gratefully acknowledge the Foundation Grenoble INP through the industrial chair GE (General Electric) "HYDRO'LIKE'.

The code "IZ" was developed at the LEGI with the support 
of the CNES (Centre National d'Etudes Spatiales).

\section{REFERENCES}

[1] Delannoy, Y., and Kueny, J., 1990. "Two phase flow approach in unsteady cavitation modelling”. Vol. 98, ASMEFED, pp. 153-158.

[2] Coutier-Delgosha, O., Fortes-Patella, R., and Reboud, J. L., 2003. "Evaluation of the turbulence model influence on the numerical simulations of unsteady cavitation". Journal of Fluids Engineering, 125(1), pp. 38-45.

[3] Fortes-Patella, R., Reboud, J., and Briancon-Marjollet, L., 2004. "A phenomenological and numerical model for scaling the flow agressiveness in cavitation erosion". In EROCAV Workshop, Val de Reuil, France.

[4] Fortes-Patella, R., Archer, A., and Flageul, C., 2012. "Numerical and experimental investigations on cavitation erosion". IOP Conference Series: Earth and Environmental Science, 15(2), Nov., p. 022013.

[5] Reisman, G. E., Wang, Y.-C., and Brennen, C. E., 1998. "Observations of shock waves in cloud cavitation". Journal of Fluid Mechanics, 355, Jan., pp. 255-283.

[6] Coutier-Delgosha, O., Reboud, J. L., and Delannoy, Y., 2003. "Numerical simulation of the unsteady behaviour of cavitating flows". International Journal for Numerical Methods in Fluids, 42(5), June, pp. 527-548.

[7] Fortes-Patella, R., Barre, S., and Jean-Luc, R., 2006. "Experiments and modelling of cavitating flows in venturi part II : Unsteady cavitation". In Proc. 6th Int. Sym. Cavitation, CAV2006, Wageningen, Netherlands.

[8] Lohrberg, H., Stoffel, B., Fortes-Patella, R., CoutierDelgosha, O., and Reboud, J., 2002. "Numerical and experimental investigations on the cavitating flow in a cascade of hydrofoils". Experiments in Fluids, 33(4), Oct., pp. 578586.

[9] Prothin, S., Billard, J.-Y., and Djeridi, H., 2016. "Image processing using proper orthogonal and dynamic mode decompositions for the study of cavitation developing on a NACA0015 foil". Experiments in Fluids, 57(10), Oct.

[10] Le, Q., Franc, J. P., and Michel, J. M., 1993. "Partial cavities: global behavior and mean pressure distribution". Journal of Fluids Engineering, 115(2), pp. 243-248.

[11] Kawanami, Y., Kato, H., and Yamaguchi, H., 1998. "Threedimensional characteristics of the cavities formed on a twodimensional hydrofoil". In Proc. 3th Int. Sym. Cavitation, CAV1998, Grenoble, France.

[12] Arndt, R. E. A., Song, C., Kjeldsen, M., He, J., and Keller, A., 2000. "Instability of partial cavitation: a numerical/experimental approach". In 23th Symposium on Naval Hydrodynamics, Val de Reuil, France.

[13] Fujii, A., Kawakami, D. T., Tsujimoto, Y., and Arndt, R. E., 2007. "Effect of Hydrofoil Shapes on Partial and Transi- tional Cavity Oscillations". Journal of Fluids Engineering, 129(6), pp. 669-673.

[14] Arndt, R. E., 2012. "Some remarks on hydrofoil cavitation". Journal of Hydrodynamics, Ser. B, 24(3), July, pp. 305-314.

[15] Arndt, R. E. A., Ellis, C. R., and Paul, S., 1995. "Preliminary investigation of the use of air injection to mitigate cavitation erosion". Journal of Fluids Engineering, 117(3), pp. 498-504.

[16] Leclercq, C., Archer, A., and Fortes-Patella, R., 2016. "Numerical investigations on cavitation intensity for $3 \mathrm{~d}$ homogeneous unsteady viscous flows". IOP Conference Series: Earth and Environmental Science, 49(9), p. 092007.

[17] Le, Q., Franc, J. P., and Michel, J. M., 1993. "Partial cavities: pressure pulse distribution around cavity closure". Journal of Fluids Engineering, 115(2), pp. 249-254.

[18] Li, Z.-r., Pourquie, M., and van Terwisga, T., 2014. "Assessment of cavitation erosion with a URANS method". Journal of Fluids Engineering, 136(4), Feb., p. 041101.

[19] Gavaises, M., Villa, F., Koukouvinis, P., Marengo, M., and Franc, J.-P., 2015. "Visualisation and LES simulation of cavitation cloud formation and collapse in an axisymmetric geometry". International Journal of Multiphase Flow, 68 , Jan., pp. 14-26. 